Pacific Journal of Mathematics

ON ALMOST EVERYWHERE CONVERGENCE OF ABEL 


\title{
ON ALMOST EVERYWHERE COVERGENCE OF ABEL MEANS OF CONTRACTION SEMIGROUPS
}

\author{
S. A. McGrath
}

Let $(X, \Sigma, \mu)$ be a $\sigma$-finite measure space and $L_{p}(X, \Sigma, \mu)$, $1 \leqq p \leqq \infty$, the usual Banach spaces of complex valued functions. Let $\left\{T_{t}: t \geqq 0\right\}$ be a strongly continuous semigroup of contractions of $L_{p}(X, \Sigma, \mu)$ for some $1 \leqq p<\infty$ and set $R_{\lambda} f=\int_{0}^{\infty} e^{-\lambda t} T_{t} f d t$, $\lambda>0$. If $\left\|T_{t}\right\|_{\infty} \leqq 1$ for all $t \geqq 0$, then $\lim _{\lambda \rightarrow \infty} \lambda R_{\lambda} f(x)=f(x)$ a.e. for all $f \in L_{p}(X, \Sigma, \mu)$.

A strongly continuous contraction semigroup on $L_{p}(X, \Sigma, \mu)$ satisfies the following: (i) $T_{s+t}=T_{s} \cdot T_{t}, s, t \geqq 0$; (ii) $\left\|T_{t}\right\|_{p} \leqq 1, t \geqq 0$; (iii) $\left\|T_{t} f-T_{s} f\right\|_{p} \rightarrow 0$ as $s \rightarrow t$ for any $f \in L_{p}=L_{p}(X, \Sigma, \mu)$. Merely as a notational convenience, we assume that $T_{0}=I$. Before proceeding further it is necessary to clarify the definition of $R_{\lambda} f(x)$. By Theorem III.11.17 in [3], given $f \in L_{p}$ there exists a scalar function $g(t, x)$, measurable with respect to the usual product measure on $[0, \infty) \times X$, such that (i) for a.e. $t, g(t, \cdot)=T_{t} f$ and (ii) there exists a $\mu$-null set $E(f)$, independent of $\lambda$, such that $x \notin E(f)$ implies $\int_{0}^{\infty} e^{-\lambda t} g(t, x) d t$, as a function of $x$, is in the equivalence class of

$\int_{0}^{\infty} e^{-\lambda t} g(t, x) d t$. The scalar representation $g(t, x)$ is uniquely determined up to a set of product measure zero. Defining $R_{\lambda} f(x)=\int_{0}^{\infty} e^{-\lambda t} g(t, x) d t$, we see that $R_{\lambda} f(x)$ is in the equivalence class of $R_{\lambda} f \stackrel{J_{0}}{=} \int_{0}^{\infty} e^{-\lambda t} T_{t} f d t$ for all $\lambda>0$. This justifies our definition of $R_{\lambda} f(x)$. Note that for $x \notin E(f), R_{\lambda} f(x)$ is a continuous function of $\lambda>0$.

The main result of this note (Theorem 4) extends a special case of a theorem of N. Dunford and J. T. Schwartz [2, p. 178]. If $p=1$ in our theorem then the assumption $\left\|T_{t}\right\|_{\infty} \leqq 1$ for $t \geqq 0$ is unnecessary [5].

\section{Preliminary results.}

LEMMA 1. Let $\left\{T_{t}: t \geqq 0\right\}$ be a strongly continuous semigroup of $L_{p}$ contractions for some $1 \leqq p<\infty$. Set $\mathscr{K}=\left\{\lambda R_{\lambda} f: 0<\lambda<\infty, f \in L_{p}\right\}$. Then $\mathscr{C}$ is dense in $L_{p}$ and $\lim _{\lambda \rightarrow \infty} \lambda R_{\lambda} f(x)=f(x)$ a.e. for any $f \in L_{p}$.

The denseness of $\mathscr{C}$ follows from the fact that $s-\lim _{2 \rightarrow \infty} \lambda R_{2} f=f$ $[4$, p. 321$]$, and the existence of the pointwise limit follows from the resolvent equation. The details appear in [5]. The next result is proved in [1]. 
LEMMA 2. Let $\left\{T_{t}: t \geqq 0\right\}$ be a strongly continuous semigroup of $L_{p}$ contractions for some $1 \leqq p<\infty$. Suppose that $\left\|T_{t}\right\|_{\infty} \leqq 1$ for all $t \geqq 0$. Then

$$
\lim _{\varepsilon \downarrow 0}\left(\frac{1}{\varepsilon}\right) \int_{0}^{\varepsilon} T_{t} f(x) d t=f(x) \text { a.e. }
$$

for every $f \in L_{p}$.

For a given $L_{p}$ semigroup $\left\{T_{t}: t \geqq 0\right\}$, define $T_{t}^{\prime}=e^{-t} T_{t}$. Then $\left\{T_{t}^{\prime}: t \geqq 0\right\}$ is a semigroup; if $\left\{T_{t}: t \geqq 0\right\}$ is strongly continuous so is $\left\{T_{t}^{\prime}: t \geqq 0\right\}$. We shall denote the resolvent of $\left\{T_{t}^{\prime}\right\}$ by $R_{\lambda}^{\prime}$. For $f \in L_{p}$, set $f^{*}=\sup _{\lambda>0}\left|\lambda R_{\lambda}^{\prime} f\right|$.

LEMma 3. Suppose $\left\{T_{t}: t \geqq 0\right\}$ is a strongly continuous contraction semigroup on $L_{p}$ for some $1 \leqq p<\infty$. If, in addition, $\left\|T_{t}\right\|_{\infty} \leqq 1$ for all $t \geqq 0$, then $f^{*}<\infty$ a.e. for any $f \in L_{p}$.

Proof. Fix $f \in L_{p}$ and choose $\left\{\varepsilon_{n}\right\}$ such that $\varepsilon_{n} \downarrow 0$. Set

$$
\begin{aligned}
& g_{n}=\inf _{\varepsilon \varepsilon_{n}}\left[\frac{1}{\varepsilon} \int_{0}^{\varepsilon} T_{t}^{\prime} f(x) d t\right], \\
& h_{n}=\sup _{\varepsilon \leqq \varepsilon_{n}}\left[\frac{1}{\varepsilon} \int_{0}^{\varepsilon} T_{t}^{\prime} f(x) d t\right], \\
& f_{\varepsilon}^{*}=\sup _{\delta \leqq \varepsilon}\left|\frac{1}{\delta} \int_{0}^{\delta} T_{t}^{\prime} f(x) d t\right| .
\end{aligned}
$$

Let $A$ be a measurable subset of $X$ with $0<\mu(A)<\infty$. Since $\left\{T_{t}^{\prime}: t \geqq 0\right\}$ satisfies the conditions of Lemma 2, we have

$$
\lim _{\varepsilon \downarrow 0} \frac{1}{\varepsilon} \int_{0}^{\varepsilon} T_{t}^{\prime} f(x) d t=f(x) \text { a.e. on } X \text {. }
$$

Hence $\lim _{n \rightarrow \infty} g_{n}=\lim _{n \rightarrow \infty} h_{n}=f(x)$ a.e. By Egoroff's theorem, given $0<\delta<\mu(A) / 2$, there exists a measurable subset $B$ of $A$ such that $\mu(B)>\mu(A)-2 \delta$ and $\left\{g_{n}\right\},\left\{h_{n}\right\}$ converge uniformly on $B$ to $f(x)$. Therefore, for some $K, n \geqq K$ implies $\left|g_{n}-f\right| \leqq 1$ and $\left|h_{n}-f\right| \leqq 1$ for all $x \in B$. Consequently $\left|g_{n}\right| \leqq|f|+1$ and $\left|h_{n}\right| \leqq|f|+1$ on $B$ for all $n \geqq K$. For given $n$, we have

$$
g_{n}(x) \leqq \frac{1}{\varepsilon} \int_{0}^{\varepsilon} T_{t}^{\prime} f(x) d t \leqq h_{n}(x)
$$

for any $\varepsilon \leqq \varepsilon_{n}$. Thus for any $x \in B$ and $n \geqq K$,

$$
\begin{aligned}
f_{*}^{*}(x) & \leqq\left|g_{n}(x)\right|+\left|h_{n}(x)\right| \\
& \leqq 2|f(x)|+2,
\end{aligned}
$$


provided $\varepsilon \leqq \varepsilon_{n}$. For some fixed $n \geqq K$, set $\delta=\varepsilon_{n}$.

By an integration by parts, we have

$$
\lambda \int_{0}^{\infty} e^{-\lambda t} T_{t}^{\prime} f(x) d t=\lambda^{2} \int_{0}^{\infty} e^{-\lambda t} t\left[\frac{1}{t} \int_{0}^{t} T_{s}^{\prime} f(x) d s\right] d t \text { a.e. on } X .
$$

For $t \geqq \delta$ we have

$$
\left|\frac{1}{t} \int_{0}^{t} T_{s}^{\prime} f(x) d s\right| \leqq \frac{1}{\delta} \int_{0}^{\infty}\left|T_{s}^{\prime} f(x)\right| d s<\infty \text { a.e. on } X
$$

since $\left\|\int_{0}^{\infty} \mid T_{s}^{\prime} f(x)\right\| d s\left\|_{p} \leqq\right\| f \|_{p}$. Hence for a.e. $x \in B$,

$$
\begin{aligned}
&\left|\lambda^{2} \int_{0}^{\infty} e^{-\lambda t} t\left[\frac{1}{t} \int_{0}^{t} T_{s}^{\prime} f(x) d s\right] d t\right| \\
& \leqq \lambda^{2} \int_{0}^{\delta} e^{-\lambda t} t[2|f(x)|+2] d t \\
&+\left(\frac{\lambda^{2}}{\delta}\right) \int_{0}^{\infty} e^{-\lambda t} t\left[\int_{0}^{\infty}\left|T_{s}^{\prime} f(x)\right| d s\right] d t \\
& \leqq {[2|f(x)|+2]\left[\lambda^{2} \int_{0}^{\infty} t e^{-\lambda t} d t\right] } \\
&+\left[\frac{1}{\delta} \int_{0}^{\infty}\left|T_{s}^{\prime} f(x)\right| d s\right]\left[\lambda^{2} \int_{0}^{\infty} t e^{-\lambda t} d t\right] \\
& \leqq\{2|f(x)|+2\}+\left(\frac{1}{\delta}\right) \int_{0}^{\infty}\left|T_{s}^{\prime} f(x)\right| d s
\end{aligned}
$$

for all $\lambda>0$. Hence $f^{*}<\infty$ a.e. on $B$. Since the set $A$ was an arbitrary set of finite measure and $B$ is a measurable subset of $A$ having positive measure, we conclude that $f^{*}<\infty$ a.e. on $X$.

Main results.

THEOREM 4. Let $\left\{T_{t}: t \geqq 0\right\}$ be a strongly continuous semigroup of $L_{p}$ contractions for some $1 \leqq p<\infty$. Suppose that $\left\|T_{t}\right\|_{\infty} \leqq 1$ for all $t \leqq 0$. If $f \in L_{p}$, then

$$
\lim _{\lambda \rightarrow \infty} \lambda R_{\lambda} f(x)=f(x) \text { a.e. }
$$

Proof. By Lemmas 1 and 3 and Banach's convergence theorem [3, p. 332-333], $\lim \lambda R_{\lambda}^{\prime} f(x)$ exists and is finite a.e. as $\lambda \rightarrow \infty$ through some countable set, say $Q^{+}$(= set of positive rationals). We recall that $\lambda R_{\lambda}^{\prime} f(x)$ depends continuously on $\lambda$ for $x$ outside some null set. Since $Q^{+}$is dense in $R^{+}$it follows that $\lim _{\lambda \rightarrow \infty} \lambda R_{\lambda}^{\prime} f(x)$ exists and is finite a.e. for all $f \in L_{p}$. Since $s-\lim _{\lambda \rightarrow \infty} \lambda R_{\lambda}^{\prime} f=f$, we must have $\lim _{\lambda \rightarrow \infty} \lambda R_{\lambda}^{\prime} f(x)=f(x)$ a.e. Upon noting that $\lim _{\lambda \rightarrow \infty} R_{\lambda} f(x)=0$ a.e. for any $f \in L_{p}$, we see that 


$$
\begin{aligned}
\lim _{\lambda \rightarrow \infty} \lambda R_{\lambda} f(x) & =\lim _{\lambda \rightarrow \infty}(\lambda+1) R_{\lambda+1} f(x) \\
& =\lim _{\lambda \rightarrow \infty} \lambda R_{\lambda}^{\prime} f(x) \\
& =f(x) \text { a.e. }
\end{aligned}
$$

The following result which generalizes Theorem 4 follows from (4.9) in [1] and the arguments used in obtaining Theorem 4.

THEOREM 5. Let $\left\{T_{t}: t \geqq 0\right\}$ be a strongly continuous semigroup of $L_{p}$ contractions for some $1 \leqq p<\infty$. Suppose there exists a measurable function $h$ on $[0, \infty) \times X$ such that

(i) $h>0$ on $[0, \infty) \times X$, and

(ii) $f \in L_{p},|f(x)| \leqq h(t, x)$ e-a.e. implies

$$
\left|T_{s} f(x)\right| \leqq h(t+s, x) \text { for all } s, t \geqq 0 \text {. }
$$

Then $\lim _{\lambda \rightarrow \infty} \lambda R_{\lambda} f(x)=f(x)$ a.e. for $f \in L_{p}$.

\section{REFERENCES}

1. J. R. Baxter and R. V. Chacon, A local ergodic theorem on $L_{p}$, Canad. J. Math., 26 (1974), 1206-1216.

2. N. Dunford and J. T. Schwartz, Convergence almost everywhere of operator averages, J. Math. and Mech., 5 (1956), 129-178.

3. — Linear Operators, part I, Interscience, New York, 1958.

4. E. Hille and R. S. Phillips, Functional Analysis and Semigroups, rev. ed., American Mathematical Society, Providence, R.I., 1957.

5. S. A. McGrath, Abelian ergodic theorems for contraction semigroups, Studia Math. (to appear).

Received April 14, 1976 and in revised form June 30, 1976.

U.S. Naval Academy

ANNAPOLIS, MARYLAND 21402 


\section{PACIFIC JOURNAL OF MATHEMATICS}

\section{EDITORS}

RICHARD ARENS (Managing Editor)

University of California

Los Angeles, California 90024

\section{R. A. Beaumont}

University of Washington

Seattle, Washington 98105
J. DugundjI

Department of Mathematics

University of Southern California

Los Angeles, California 90007

D. Gilbarg and J. Milgram

Stanford University

Stanford, California 94305

\section{ASSOCIATE EDITORS}
E. F. BECKENBACH
B. H. NeumanN
F. WOLF
K. YosHIDA

\section{SUPPORTING INSTITUTIONS}

\author{
UNIVERSITY OF BRITISH COLUMBIA \\ CALIFORNIA INSTITUTE OF TECHNOLOGY \\ UNIVERSITY OF CALIFORNIA \\ MONTANA STATE UNIVERSITY \\ UNIVERSITY OF NEVADA \\ NEW MEXICO STATE UNIVERSITY \\ OREGON STATE UNIVERSITY \\ UNIVERSITY OF OREGON \\ OSAKA UNIVERSITY
}

\author{
UNIVERSITY OF SOUTHERN CALIFORNIA \\ STANFORD UNIVERSITY \\ UNIVERSITY OF HAWAII \\ UNIVERSITY OF TOKYO \\ UNIVERSITY OF UTAH \\ WASHINGTON STATE UNIVERSITY \\ UNIVERSITY OF WASHINGTON \\ AMERICAN MATHEMATICAL SOCIETY
}

The Supporting Institutions listed above contribute to the cost of publication of this Journal, but they are not owners or publishers and have no responsibility for its content or policies.

Mathematical papers intended for publication in the Pacific Journal of Mathematics should be in typed form or offset-reproduced, (not dittoed), double spaced with large margins. Please do not use built up fractions in the text of your manuscript. You may however, use them in the displayed equations. Underline Greek letters in red, German in green, and script in blue. The first paragraph or two must be capable of being used separately as a synopsis of the entire paper. Items of the bibliography should not be cited there unless absolutely necessary, in which case they must be identified by author and Journal, rather than by item number. Manuscripts, in triplicate, may be sent to any one of the editors. Please classify according to the scheme of Math. Reviews, Index to Vol. 39. All other communications should be addressed to the managing editor, or Elaine Barth, University of California, Los Angeles, California, 90024.

The Pacific Journal of Mathematics expects the author's institution to pay page charges, and reserves the right to delay publication for nonpayment of charges in case of financial emergency.

100 reprints are provided free for each article, only if page charges have been substantially paid. Additional copies may be obtained at cost in multiples of 50 .

The Pacific Journal of Mathematics is issued monthly as of January 1966. Regular subscription rate: $\$ 72.00$ a year (6 Vols., 12 issues). Special rate: $\$ 36.00$ a year to individual members of supporting institutions.

Subscriptions, orders for back numbers, and changes of address should be sent to Pacific Journal of Mathematics, 103 Highland Boulevard, Berkeley, California, 94708.

PUBLISHED BY PACIFIC JOURNAL OF MATHEMATICS, A NON-PROFIT CORPORATION

Printed at Kokusai Bunken Insatsusha (International Academic Printing Co., Ltd.), 8-8, 3-chome, Takadanobaba, Shinjuku-ku, Tokyo 160, Japan. 


\section{Pacific Journal of Mathematics \\ Vol. 65, No. $2 \quad$ October, 1976}

Andrew Adler, Weak homomorphisms and invariants: an example .......... 293

Howard Anton and William J. Pervin, Separation axioms and metric-like

functions ............................................. 299

Ron C. Blei, Sidon partitions and p-Sidon sets .................... 307

T. J. Cheatham and J. R. Smith, Regular and semisimple modules ........... 315

Charles Edward Cleaver, Packing spheres in Orlicz spaces .............. 325

Le Baron O. Ferguson and Michael D. Rusk, Korovkin sets for an operator on a

space of continuous functions ............................. 337

Rudolf Fritsch, An approximation theorem for maps into Kan fibrations ....... 347

David Sexton Gilliam, Geometry and the Radon-Nikodym theorem in strict

Mackey convergence spaces .................................

William Hery, Maximal ideals in algebras of topological algebra valued

functions ...................................... 365

Alan Hopenwasser, The radical of a reflexive operator algebra ........... 375

Bruno Kramm, A characterization of Riemann algebras................. 393

Peter K. F. Kuhfittig, Fixed points of locally contractive and nonexpansive

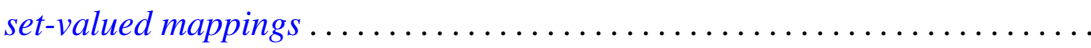

Stephen Allan McGrath, On almost everywhere convergence of Abel means of

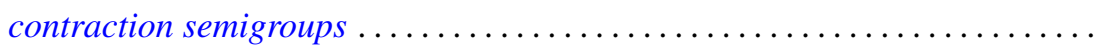

Edward Peter Merkes and Marion Wetzel, A geometric characterization of

indeterminate moment sequences............................ 409

John C. Morgan, II, The absolute Baire property ................... 421

Eli Aaron Passow and John A. Roulier, Negative theorems on generalized convex approximation .................................... 437

Louis Jackson Ratliff, Jr., A theorem on prime divisors of zero and characterizations of unmixed local domains ..............

Ellen Elizabeth Reed, A class of $T_{1}$-compactifications................... 471

Maxwell Alexander Rosenlicht, On Liouville's theory of elementary

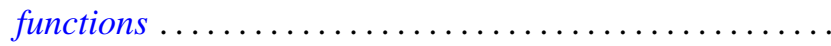

Arthur Argyle Sagle, Power-associative algebras and Riemannian

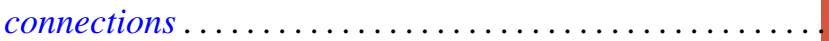

Chester Cornelius Seabury, On extending regular holomorphic maps from Stein manifolds...

Elias Sai Wan Shiu, Commutators and numerical ranges of powers of operators ...................................

Donald Mark Topkis, The structure of sublattices of the product of $n$ lattices ... 525

John Bason Wagoner, Delooping the continuous $K$-theory of a valuation

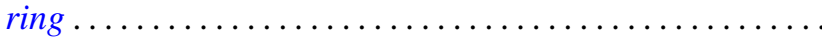

Ronson Joseph Warne, Standard regular semigroups...........

Anthony William Wickstead, The centraliser of $E \otimes_{\lambda} F \ldots$. 